
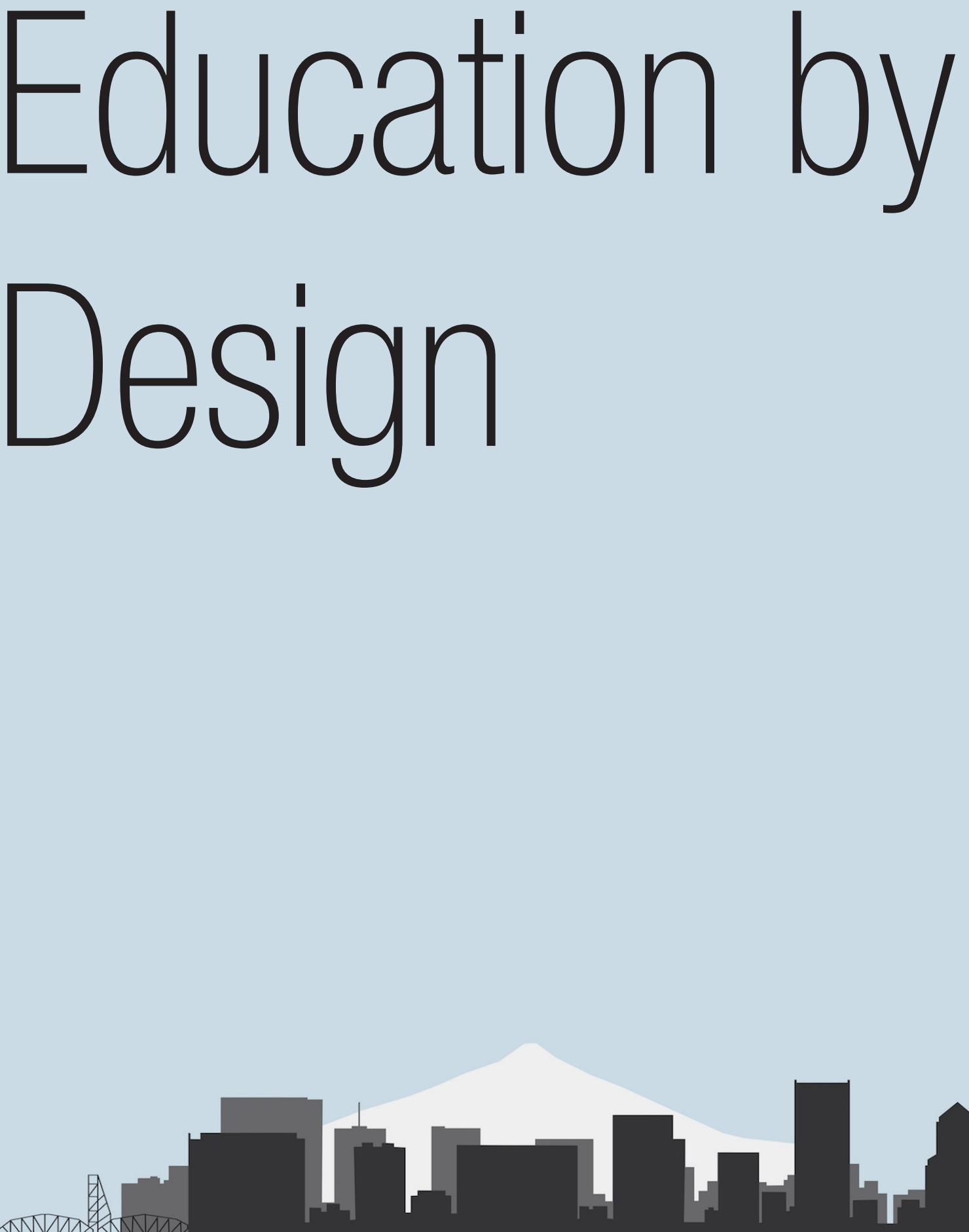

2019 Reynolds Symposium: Education by Design October 18-20, 2019 


\section{Organizing Committee:}

[co-organizers]

Professor Alison Kwok, Ph.D, FAIA, University of Oregon

Emeritus Professor John Reynolds, FAIA, University of Oregon

\section{[Symposium coordinator]}

Isabel Rivera, Ph.D., University of Oregon

Professor Walter Grondzik, P.E., Ball State University

Professor Bruce Haglund, AIA Assoc., University of Idaho

Assistant Professor Emily McGlohn, AIA, Auburn University

Associate Professor Ulrike Passe, lowa State University

Assistant Professor Siobhan Rockcastle, Ph.D., University of Oregon

Sharon Refvem, FAIA, LEED Fellow, Senior Associate and Director, Sustainability Resource Group, Hawley Peterson Snyder 


\title{
Evaluating indoor environmental quality and energy performance of LEED certified buildings
}

\author{
Jaya Mukhopadhyay, PhD \\ Assistant Professor \\ School of Architecture \\ Montana State University \\ Bozeman, Montana \\ jaya.mukhopadhyay@montana.edu
}

\author{
Duke Elliott \\ Resource Conservation \\ Specialist \\ University Facilities \\ Montana State University \\ Bozeman, Montana \\ duke.elliott@montana.edu
}

\author{
Shannon Sanderson \\ Graduate Student \\ School of Architecture \\ Montana State University \\ Bozeman, Montana \\ shannon.sanderson@ \\ montana.edu
}

\begin{abstract}
This paper describes the pedagogical findings of a class that was developed to evaluate the indoor environmental quality (IEQ) and energy performance of Green buildings. The class aimed to establish a hands-on experience for students of architecture and engineering in evaluating the physical performance of the different building systems. In order to perform the evaluation, conditions were created for the students of both programs to work together and assess the performance of buildings in terms of IEQ and energy consumption. Students conducted various studies to evaluate the IEQ and energy performance of two LEED certified Green buildings on the Montana State University campus in Bozeman Montana. The performance of selected buildings was evaluated using established metrics, measurement protocols and calibrated instruments. Finally, recommendations were made to reduce energy usage and improve IEQ of these buildings. Based on the assessments of these buildings, general guidelines and recommendations were compiled in a final report for architects and engineers to design and operate Green buildings. From this experience, the students learned about the importance of, as well as the correlation between energy efficiency and IEQ in LEED certified buildings. The class was conducted in a flip classroom format, the instructional material was delivered online and the students were required to utilize this information to conduct relevant activities during class time.
\end{abstract}

\section{INTRODUCTION}

Green buildings address energy reduction by implementing energy efficiency measures and ensuring optimal operation of building systems, while also assuring acceptable IEQ. However, many of the requirements in such buildings to ensure optimal IEQ often counteract the requirements for energy efficiency. Several studies in the subject of sustainable design, construction, and operation Green buildings have focused on validating the conservation and cost savings i.e., energy, water, and natural materials. However, the evaluation of resultant IEQ in these buildings is often ignored and very little information is available as to how these buildings perform in terms of IEQ after the building has been occupied (Lee and Kim 2008). In addition, there are very few studies focusing on the occupants' evaluation on whether these criteria contribute to their satisfaction and performance in the LEEDcertified Green buildings (Lee and Guerin 2010). The above discussion demonstrates a need for a combined evaluation of the energy and IEQ performance of Green buildings in order to ensure efficient operation of buildings and occupant comfort.

A course developed at the School of Architecture, Montana State University to execute a part of the $14^{\text {th }}$ National Student Design Competition focusing on People, Planet and Prosperity sponsored by Environmental Protection Agency that aimed to evaluate the IEQ and energy performance of LEED certified buildings (Mukhopadhyay et al., 2019). The course highlighted the importance of an interdisciplinary approach that utilizes methods and analytical frameworks from the disciplines of both architecture and mechanical engineering to examine the issue of building performance, with the intention of forming a more wholesome method of analysis that offers a richer understanding of the issue at hand (Goldsmith et al., 2018). In order to perform the evaluation, conditions were created for the students of 
architecture and engineering programs on campus to work together and assess the performance of buildings in terms of energy consumption and IEQ.

\section{GOALS AND OBJECTIVES}

The objective of this paper is to present the structure and organization of an interdisciplinary class consisting of students of architecture and engineering, which provided a hands-on experience to evaluating the physical performance of the different building systems in Green buildings. In addition, the objective is to present the challenges faced and the lessons learned from the methods used in disseminating the material presented in this class. Finally, the paper provides recommendations to improve the outcomes of future iterations of this class.

\section{STRUCTURE AND ORGANIZATION OF THE CLASS}

The structure and organization of the class was derived from the road map developed towards the execution of this research project. The class size was limited to 8 students from the architecture and engineering undergraduate and graduate programs. The course goals, objectives and format of the class contributed to addressing the different segments of this roadmap.

\section{Overview of the Research Project: Methodology}

In order to conduct the analysis, two buildings with similar functions (dormitories) were selected on the MSU campus. These two buildings were selected because of their performance in meeting the criteria for LEED certification. More specifically, each building was reviewed in terms of their compliance with criteria specified for IEQ and energy as described in the LEED Version 3 certification process. Criteria for LEED V4 certification was also used to establish an updated benchmark for LEED certification.

The IEQ analysis was taken up by the architecture students and the energy analysis was performed by the engineering students. A preliminary walkthrough was conducted through the buildings during which time the strategies to reduce energy consumption and improve IEQ were noted. The students then formulated individual hypotheses based on their observations from the initial walkthrough and background information including construction drawings provided to them. The formulated hypotheses were evaluated using methods and metrics established in the ASHRAE Performance Measurement Protocols (2010) and ASHRAE Commercial Building Audits (2011). Energy data was made available from the Montana State University Engineering and Utilities. Methods and metrics established in the ASHRAE Performance Measurement Protocols that were used in the analysis included: documenting observations from the checklists compiled from subsequent walk-throughs, analysis of collected data, measurement of various parameters associated with IEQ and post occupancy surveys of the occupants. Metrics established in the ASHRAE Commercial Building Audits that were used in this analysis included the use of Energy Use Index with comparisons to CBECS data as well as localized campus building comparisons. The results from the observations, data and surveys were compiled and evaluated using various statistical and graphical methods of analysis. Final recommendations were based from these conclusions. Various resources from ASHRAE and EPA were consulted to inform these recommendations. An overview of the methodology adopted for this study is presented in Figure 1.

\section{Overview of the Interdisciplinary Class: Goals, Learning Outcomes and Format}

The goals of this course are the following:

1. Gain a hands-on experience in measuring, documenting and evaluating IEQ and energy consumption in Green Buildings

2. Learn to appreciate the intricate correlation between IEQ and energy efficiency in Green Buildings

3. Recommend appropriate strategies to improve IEQ and energy efficiency in Green Buildings

4. Have the opportunity to work in an interdisciplinary environment and to actively participate in classroom presentations and discussions. 
When writing the outcomes of this class, it was helpful to create outcomes that are measurable, or that describe an observable action through a set of action verbs. Observable actions are often indicated by action verbs that correspond to cognitive processes and knowledge categories, as described by Bloom's Taxonomy, which is a multi-tiered model for classifying thinking by six levels of cognitive complexity (Bloom 1956, Anderson and Krathwohl 2001). Arranged in order of increasing sophistication, they are: Remembering, Understanding, Applying, Analyzing, Evaluating, and Creating. Utilizing variations of the above mentioned action verbs, the following learning outcomes were determined in order of the class format:

1. Understand concepts of IEQ and energy performance in buildings

2. Identify issues with IEQ and energy consumption in Green Buildings

3. Understand and apply different building performance measurement protocols

4. Set up experiments to measure variables, and evaluate resultant trends in variables

5. Conduct post occupancy evaluation survey and evaluate results obtained from these surveys

6. Evaluate information related to building performance by use various graphical and statistical tools

7. Communicate information related to building performance to engineers and others

8. Recall the different strategies to improve IEQ and energy efficiency in buildings

The class format focused on walking the student through evaluating building performance using a flipped classroom format ${ }^{1}$. In this format the information was posted online on a learning management system ${ }^{2}$ used by the class at the beginning of every week. A new topic was introduced every week in form of lecture notes. In addition to the information presented, the lecture notes had a slide each on the objectives accomplished by the information presented, required classwork for the week, the weekly assignments, and the contribution that the students had to make that week to the ongoing compilation of the report. The students got time to process the information, ask questions and have discussions using the online message board provided by this online environment. The class then met every Friday for a period of three hours. The 15 week long semester was divided into four segments at the end of which major milestones were reached. The engineering and architecture students got together every five weeks and presented their findings to each other. Conditions were created to encourage questions and facilitate a free exchange of ideas. An overview of the class structure and its integration to address the questions of the research project is presented in Figure 1.

\section{Teaching Topics, Class Activities, and Assignments}

Various topics were introduced on a weekly basis to the students of architecture and engineering, which would contribute to their understanding of building performance and assist them in conducting an evaluation of building performance. The students were required to conduct class and on-site activities during the time allotted for the class. Students were also required to complete the assignments that were introduced on a weekly basis during this time. The assignments addressed different components of the research project and were ultimately integrated into a Final Report submitted by the students as a class at the end of the semester. For IEQ, the topics included:

1. IEQ in LEED rating system

2. Standards, codes and guidelines for IEQ

3. Measurement instruments and methods

4. Performance measurement protocols

5. Post occupancy surveys

6. Data analysis and evaluation

7. Strategies to improve IEQ in buildings

${ }^{1}$ Flipped classroom format is an instructional strategy that reverses the traditional learning environment by delivering instructional material online and conducts activities which involve synthesizing, analyzing and problem-solving in class (Brame 2013).

2 A learning management system (LMS) is a software application for the administration, documentation, tracking, reporting, and delivery of educational courses, training programs, or learning and development programs (Ellis 2009). 
8. Correlation of strategies for IEQ and energy in buildings

For energy performance assessment, topics included:

1. Introduction to Building Energy Assessment

2. EUI and calculations

3. Overview of MSU resource use, campus meters and utility data

4. Preliminary Energy Use Analysis

5. Introduction to deep retrofits

6. HVAC controls

Class Organization (Week 1-4): In the initial stages of the class, the students were asked to conduct preliminary evaluations of the case-study buildings by perusing construction drawings and conducting a preliminary walk-through. The intention was to compile preliminary observations and to formulate hypothesis for the different components of IEQ based off these observations. The students were then asked to identify different IEQ categories of compliance with LEED (USGBC 2009, 2013).

Class Organization (Week 5-8): Various instruments that are used for measuring different components of IEQ were introduced in class. Students were asked to formulate simple hypothesis and conduct short exercises proving the established hypothesis. The material for short exercises was adopted from a similar class conducted at University of Idaho (Haglund 2019). The students were then asked to compile 5 minute presentations of the results from the exercises highlighting the potential capabilities and limitations of each instrument.

Class Organization (Week 9-12): ASHRAE performance measurement protocols were presented to the students (ASHRAE 2010). Based on the description of basic-level performance measurement protocols provided in the notes, the students were asked to design and develop experiments that could be used to evaluate the different components of IEQ. The protocols would be implemented in the case-study buildings to test the hypothesis that was formulated by the students in the first week of class. Postoccupancy surveys for the case-study buildings were prepared in collaboration with University of California Center for Built Environment UC CBE (CBE 2018). Students were asked to modify and tailor the survey based on specific requirements of the buildings. The

Class Organization (Week 13 - 14): Several graphical and statistical methods of data analysis were presented to the students. In addition to the different types of graphical formats available in Microsoft Excel, information was compiled from several resources, which include excerpts from 'Elements from Graphing Data' (Cleveland 1994), 'Exploratory Data Analysis' (Tukey 1977), and "ASHRAE Guideline-14, Measurement of Energy, Demand, and Water Savings" (ASHRAE 2014). Students were encouraged to use this information in organizing the data obtained from the experiments conducted and the post occupancy evaluation survey. Strategies to improve IEQ in buildings were compiled from several resources, which include resources such as: 'Sound Matters: How to Achieve Acoustic Comfort in the Contemporary Office' (GSA 2011) for acoustics, 'Guide to setting thermal comfort criteria and minimizing energy use in delivering thermal comfort' for thermal comfort (Regnier 2012), 'Daylighting Pattern Guide' for daylighting (NBI 2017) and 'Indoor Air Quality Guide' (ASHRAE 2009) for IAQ. Sessions were held in class where students engaged in discussing and sharing their thoughts on different strategies and the potential synergies between these strategies. Finally, correlating strategies for IEQ and energy consumption were compiled from International Performance Measurement and Verification Protocols Concepts and practices for improved indoor environmental quality, Volume II (2001). Using this information students were able to document the correlation between the proposed IEQ strategies with the energy consumption profiles for these case-studies.

In addition, strategies for the engineering analysis included the development of utility data into usable formats, calculating EUIs and comparing cost and energy consumption collectively and individually per utility source type. For example, students were guided in the development of both EUI numbers as well as the examination of cost per fuel type and cost per building. Engineering students relied on classroom instruction, assignments and the use of Procedures for Commercial Building Energy Audits (ASHRAE 2011). Engineering students also conducted field visits of the buildings and interviewed maintenance personnel to obtain actual operating conditions in each building. 
EPA P3 Research Project

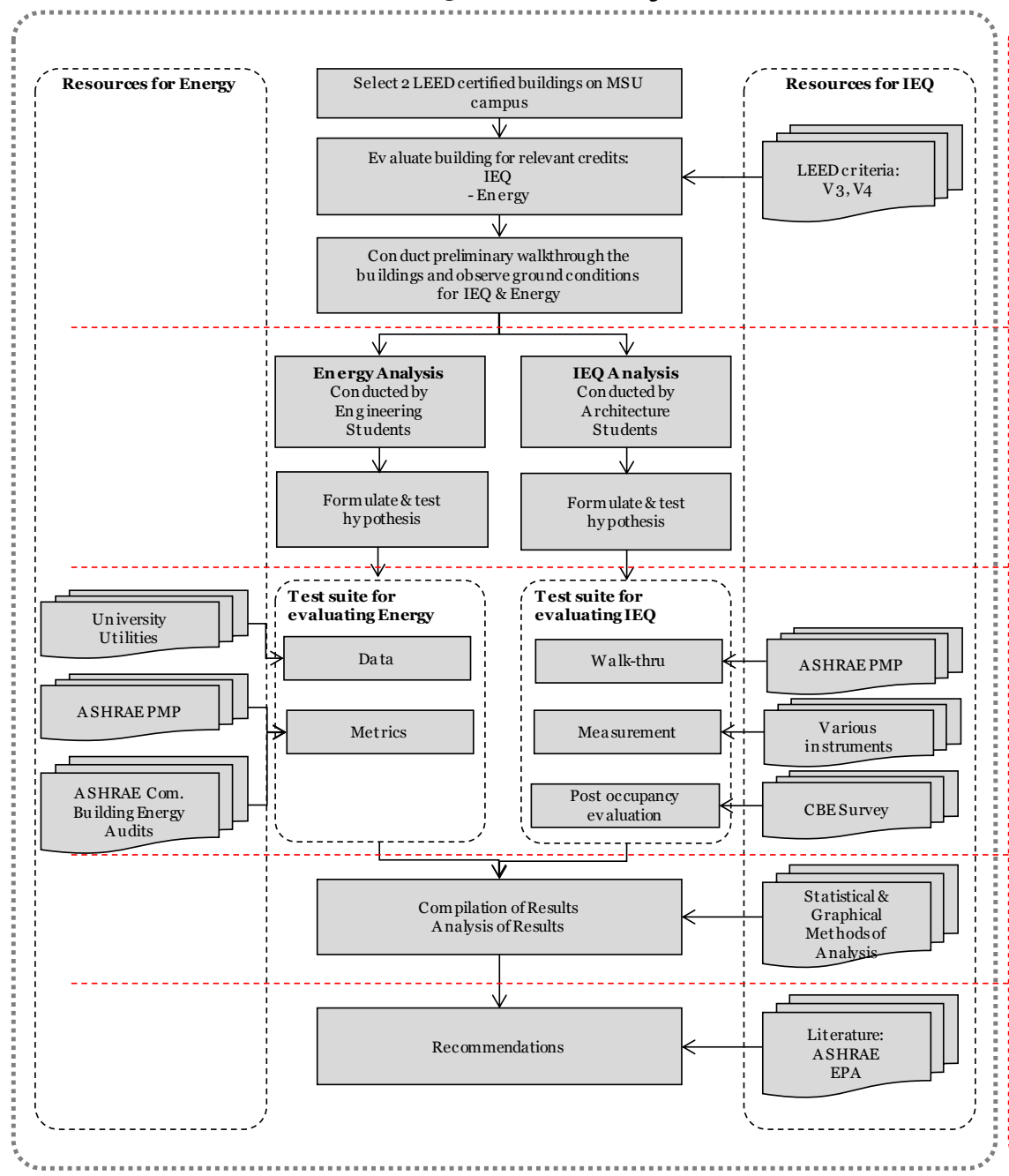

ARCH / ENGG Class Organization

\begin{tabular}{|c|c|c|c|}
\hline $\begin{array}{l}\text { Introduction toIEQ. } \\
\text { IEQ in LEED rating system. } \\
\text { Standards, codes \& guidelines for IEQ. }\end{array}$ & $\begin{array}{l}\text { Perusal of construction drawings. } \\
\text { Preliminary wallthrough. } \\
\text { Documentation of observations from } \\
\text { dr awings\& walkthrough. } \\
\text { Formulation of hypothesis. } \\
\text { Identify different categories of IEQ } \\
\text { selected for LEEED compliance. } \\
\text { Wallhthrough to evaluate compliance } \\
\text { with LEED. }\end{array}$ & $\begin{array}{l}\text { 1. CITI training } \\
\text { 2. Ca se-study description } \\
\text { 3. Formulation of hypothesis } \\
\text { 4.Compliance w/ LEED criteria for } \\
\text { IEQ }\end{array}$ & 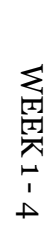 \\
\hline Mea surement instruments \& methods. & $\begin{array}{l}\text { In-class exercise exploring the use of } \\
\text { in struments. }\end{array}$ & $\begin{array}{l}\text { 5. A note on the instruments used to } \\
\text { evaluate IEQ } \\
\text { 6. Sketchexercises (SOURCE) } \\
\text { : Acoustics } \\
\text { Thermal comfort } \\
\text { - IAQ } \\
\text { Lighting }\end{array}$ & $\begin{array}{l}\sum_{1}^{1} \\
\text { 臭 } \\
\text { G } \\
1 \\
\infty\end{array}$ \\
\hline Per formance measurement protocols. & $\begin{array}{l}\text { Using instruments develop experiment } \\
\text { to test hypothesis. } \\
\text { Deploy experiment on sites. } \\
\text { Refine POE compiled by UC CBE. } \\
\text { Deployment of survey. }\end{array}$ & $\begin{array}{l}\text { 7. Development of ASHRAE basic level } \\
\text { per formance measurement } \\
\text { protocols for: } \\
\text { : coustics } \\
\text { Therral comfort } \\
\text { IAQ } \\
\text { Lighting }\end{array}$ & $\begin{array}{l}\sum_{1}^{1} \\
\text { 黄 } \\
0 \\
1 \\
N\end{array}$ \\
\hline Data analysis \& evaluation. & $\begin{array}{l}\text { Bra instorm to select appropriate } \\
\text { techniquesto appropriately represent } \\
\text { collected data. }\end{array}$ & $\begin{array}{l}\text { 8. Documentation of results from data } \\
\text { collected from experiments \& } \\
\text { su rvey. }\end{array}$ & $\sum$ \\
\hline Strategies to improve $\mathbb{E Q}$ in buildings. & $\begin{array}{l}\text { Bra ainstorm recommendations to } \\
\text { im prove IEQ \& energy consumption in } \\
\text { bu ildings. }\end{array}$ & $\begin{array}{l}\text { 8. Recommendations \& strategiesto } \\
\text { im prove IEQ in buildings. }\end{array}$ & $\frac{\omega}{\omega}$ \\
\hline $\begin{array}{l}\text { Correlation of strategies for IEQ and } \\
\text { en ergy in buildings. }\end{array}$ & $\begin{array}{l}\text { Class discussion on correlating } \\
\text { strategiesfor IEQ \& energyin } \\
\text { bu ildings. }\end{array}$ & & $\vec{\perp}$ \\
\hline
\end{tabular}

Figure 1. Overview of the methodology adopted for the research and resultant ARCH / ENGG class structure. 


\section{EXCERPTS FROM STUDENT WORK}

The following subsections present excerpts of student work that contributed to this research. The excerpts present the methodology adopted and the results from evaluating the IAQ component of IEQ. Similar procedures were followed to evaluate energy and other components of IEQ. An edited version of the work is presented in the following sections.

\section{Walk-through Analysis and Hypothesis for IAQ in Case-study Buildings}

On conducting a preliminary walkthrough of the two case study buildings, all spaces observed were clean and functioning as they should, which indicated that the mechanical equipment is implementing the correct air exchanges required for spaces with mechanical ventilation. Based on observations, two hypotheses were formulated, which are documented below:

1. Without a forced air ventilation system, the rooms will become stuffy and malodorous.

2. The heating system will work overtime to compensate for open windows in cold months.

\section{Objectives and Methodology Adopted to Evaluate IAQ in Case-study Buildings}

In order to evaluate IAQ in the two case-study buildings, the differences between living quarters with a forced air system and living quarter without a forced air system were considered. An overview of the implementing the ASHRAE PMP by this study to address these objectives is provided in Figure 2 below.

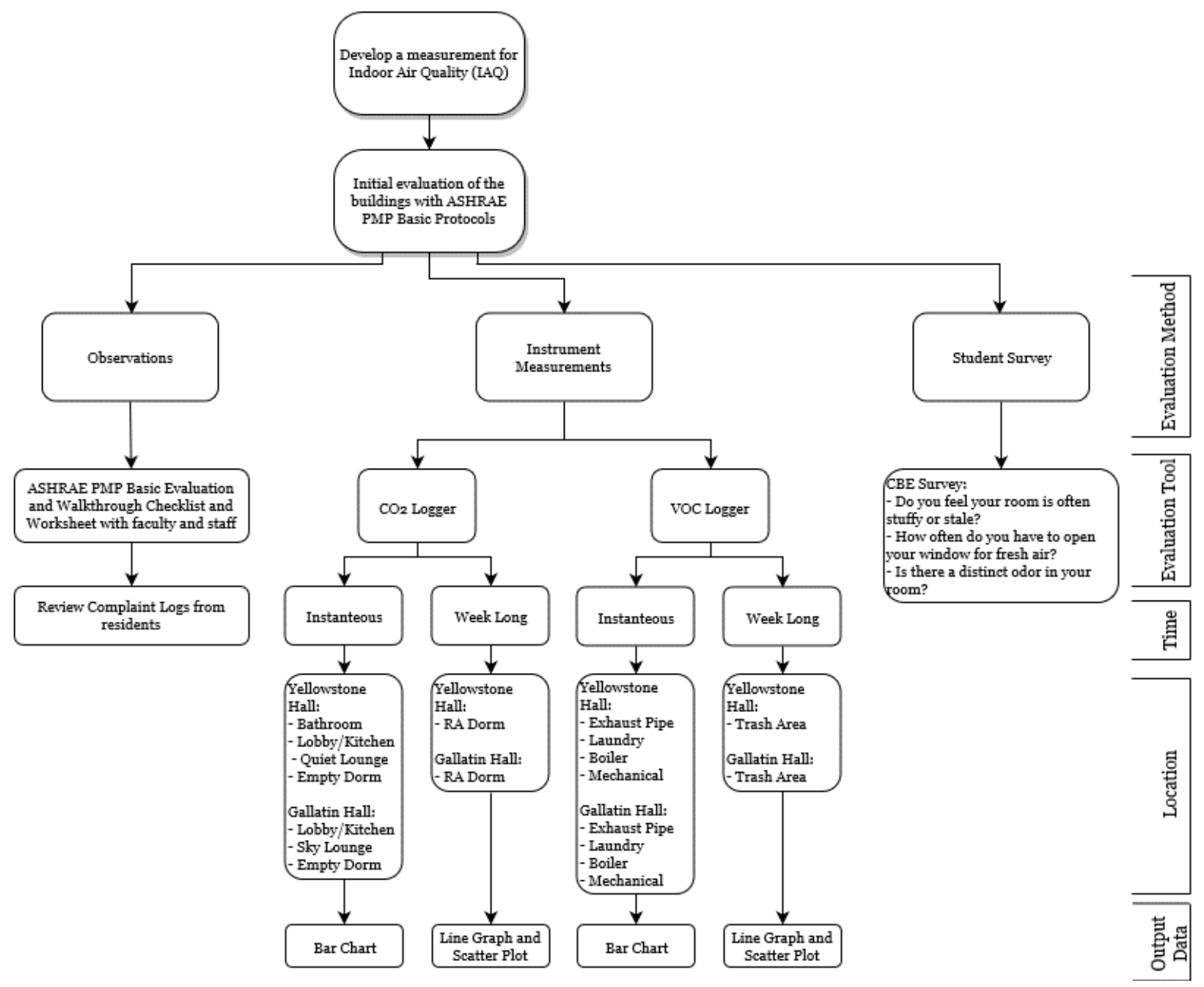

Figure 2. Flowchart Indicating the Use of ASHRAE PMP for Evaluating IAQ Conditions. 


\section{Measurement for IAQ - Logged measurement}

Logged measurements were taken in both the case-study buildings during different weeks of the Fall 2018 semester. For each measurement, the instrument logged the $\mathrm{CO} 2$ level in a dorm room every 15 minutes for a minimum of 4 days3. Typical exterior $\mathrm{CO}_{2}$ levels range from $300 \mathrm{ppm}$ and $400 \mathrm{ppm}$ (ASHRAE 2013). For Building A (Figure 3), the majority of $\mathrm{CO} 2$ measurements were in the $500 \mathrm{ppm}$ to $600 \mathrm{ppm}$ range and nothing higher than $850 \mathrm{ppm}$ or lower than $350 \mathrm{ppm}$ was measured. For Building B (Figure 3), the majority of $\mathrm{CO}_{2}$ measurements were in the $350 \mathrm{ppm}$ to $450 \mathrm{ppm}$ range and nothing lower than 350 ppm, but at some instances $\mathrm{CO} 2$ levels as high as 1400 ppm were observed. Based on ASHRAE Standard 62.1, the limit of acceptable interior $\mathrm{CO} 2$ levels are $700 \mathrm{ppm}$ above exterior levels (ASHRAE 2013). Hence, based on current $\mathrm{CO} 2$ levels, anything above $1100 \mathrm{ppm}$ is an increase in health risks. Out of the 96 hours logged for Building B, 3 hours were above acceptable levels.

When considering the correlations between outside air (OA) temperature and $\mathrm{CO} 2$ levels in Building A, as $\mathrm{OA}$ temperature increases, the $\mathrm{CO} 2$ levels decrease to a certain point after which spikes in $\mathrm{CO} 2$ levels are observed. This is because occupants keep their windows closed during periods of very cold and very hot OA temperatures, but open during moderate OA temperatures. In addition, the air circulation provided by the forced air system to the spaces maintained the $\mathrm{CO} 2$ levels within an acceptable range. A different trend in $\mathrm{CO} 2$ levels was observed for Building $\mathrm{B}$. The absence of forced air system delivering ventilation air to spaces caused spikes in $\mathrm{CO} 2$ levels at all instances of $\mathrm{OA}$ temperatures, which implies occurences when residents entered the room with a closed window and spent some time in an unventilated environment before opening the windows. It should be noted that by collecting data in two separate weeks, the temperatures are drastically different, which leads us to interpret the data with some skepticism. The hypotheses would ideally be tested in cold weather in both buildings where opening a window is less likely to be an option.
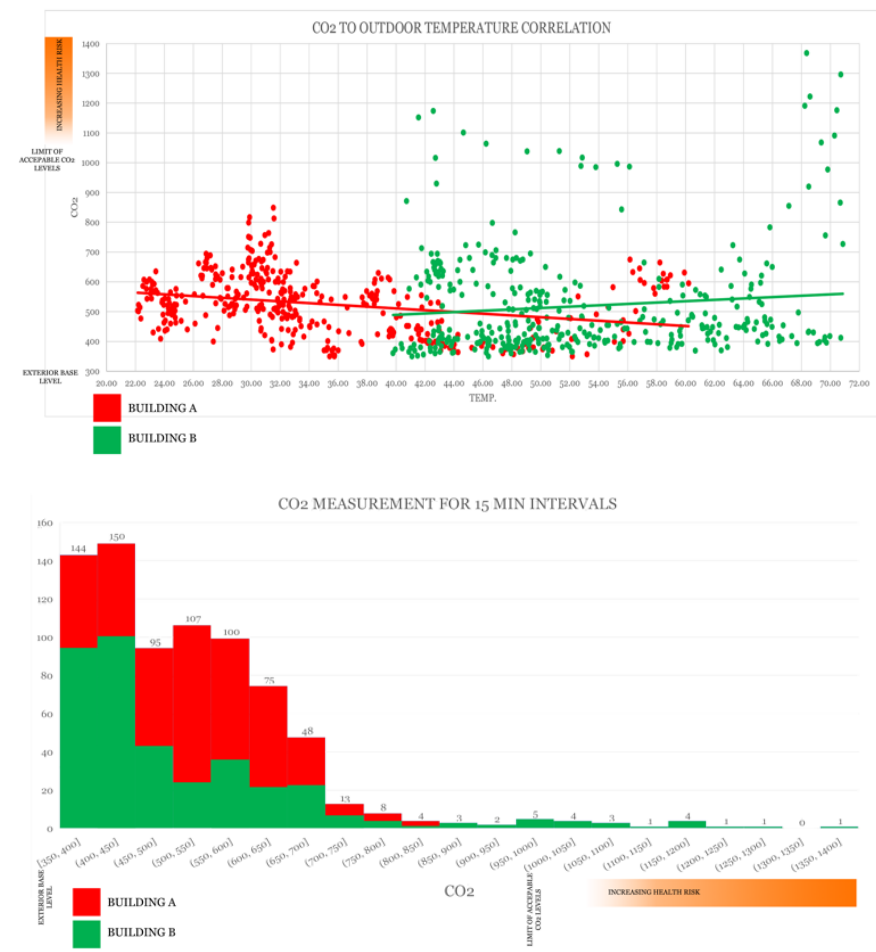

Figure 3. Scatterplot (Top) and Histogram (Bottom) Evaluation of $\mathrm{CO}_{2}$ Levels at Hall A and Hall B Dorm Rooms.

\section{Post-occupancy Survey for evaluating IAQ}

${ }_{3} \mathrm{CO} 2$ concentrations are a good indicator of indicator of occupant odors (odorous bioeffluents). 
The post occupancy survey (Figure 4) was to provide insight on how the occupants utilize the space and how they feel about ventilation in their dorms as well as any specific complaints. The results of the survey added to an understanding on how residents with forced air systems view their IAQ compared to how residents without forced air systems view their IAQ. The survey shows that $64 \%$ of Building B residents spend 8-15 hours in the residence hall and 30\% spend less than 8 hours. For Building A, 80\% spend 8-15 hours in the residence hall and $7 \%$ spend less than 8 hours. The survey also shows that $26 \%$ of Building B Residents spend little to no time in their bedrooms, while only $19 \%$ of Building A Residents spend little to no time in theirs. The higher rates of time in Building A over Building B could endorse the notion of enhanced comfort in the Building A. In addition, there may be other variables at play given the complexity of student occupancy, building type, room layout and a multitude of other factors.

The majority of participants from both buildings reported satisfaction with their air quality in their living spaces, however there is a larger percentage that is dissatisfied in Building B than Building A. Also, out of the people that were dissatisfied with the IAQ, more people in Building A felt it was detrimental to their comfort and productivity. Both buildings declared stuffiness and odor as the major problems with the air quality. Odor can be caused by many different things. The leading causes reported by Building A residents was determined to be tobacco smoke, furniture and carpet off-gassing and food odors. The leading causes reported by Building B residents was determined to be body and food odors. For Building A the main concern appears to be that the windows do not open nearly enough to help in regulating heat and air flow. Typical complaints about air quality in Building B include stagnant and stuffy air as well as lack of air flow and high dust pollution. When asked to "Please describe any other issues related to the ease of using operable windows that are important to you." $50 \%$ of Building B stated that they fear opening their windows due to threats of harming the heaters and causing costly damages, some even stated that they do it regardless because the rooms get so hot and stuffy. The concern about harming the heaters is valid when the rooms are unoccupied during extended breaks but is a prime example of how communicating one building operations issue can negate a building feature (in this case operable windows) that is integral to the original design.

How satisfied are you with the air quality in your unit? (i.e., stuffy/ stale air, cleanliness, odors)

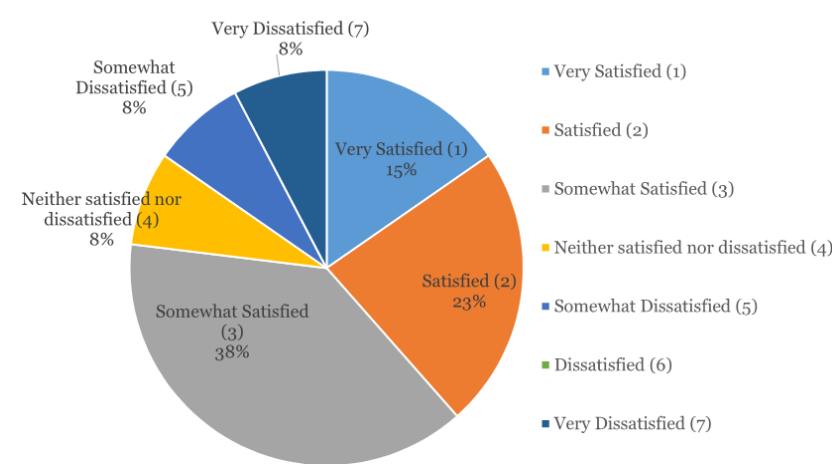

How satisfied are you with the air quality in your unit? (i.e., stuffy/ stale air, cleanliness, odors)

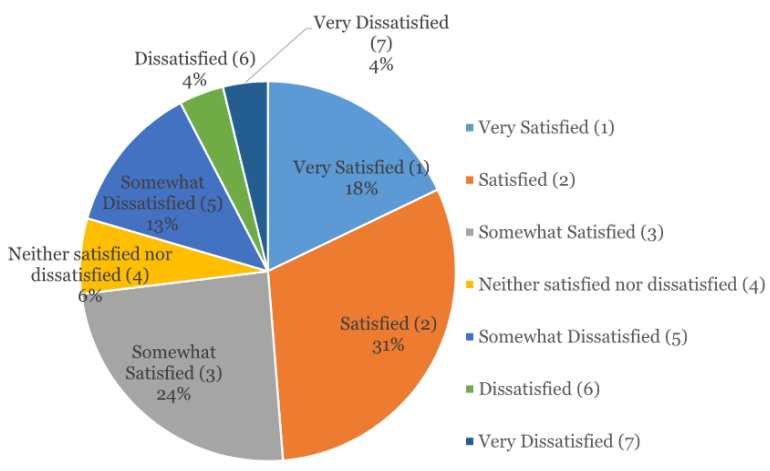

Figure 4. Snapshots of Survey Results for Indoor Air Quality at the Building A (left) and B (right).

\section{Recommendations for IAQ}

There are several reasons for poor IAQ within built environments, which include tight building construction schedules, prioritization of IAQ in the design and construction of buildings, selection and type of HVAC system. Some general recommendations to improve IAQ include: inclusion of IAQ along with all other IEQ measures when deciding priorities in the design and construction process; correct selection and sizing of HVAC equipment in the building to ensure adequate supply of outdoor air and regulating humidity levels; design and placement of outdoor air intakes, avoiding placement of near potential contaminants (ASHRAE 2009). 
When considering more specific recommendations, for Building B, during the logged measurements of the sample dorm room there were on average an hour a day where the $\mathrm{CO} 2$ levels were above acceptable limits. While the corridors and bathrooms are mechanically ventilated, the rooms do not have provisions for air distribution systems. This is an issue because the dorm rooms have to rely on appropriate weather conditions to be able to ventilate their living spaces. On the other hand introducing duct work into each dorm room may have its own limitations in terms of cost considerations, spatial limitations and appropriate acoustical treatment. A feasible retrofit may include adding louvers to the doors to allow for passive ventilation to happen more easily if the door is closed. However, adding louvers to the doors may have an adverse effect on acoustics and privacy that needs to be considered. Also, when considering the use of transpired solar collectors for preheating ventilation air, the southern part of the building is favorable for their location. The southern part of the site is also a great place for parking lots to reduce snow build up in the cold months. Parking lots and outdoor air intakes are not favorable to be within the same vicinity. One recommendation is to place the parking toward the North West façade if possible and the intakes on the south façade, keeping the intakes as far from the contaminants as possible.

\section{LESSONS LEARNED}

Several key lessons were learned from evaluating the content and structure of the course, the interdisciplinary interactions facilitated by this course, and use of research to innovate educational experience of students in this course. Observations of the instructors and student feedback provided valuable insights into how this course could be improved in the future.

\section{Class Content and Structure}

For the architectural segment of the class, several engineering concepts such as: diagnostic measurement, graphical assessment of data, and basic principles of building physics had to be understood and applied into the process of investigation. While it was impossible to cover all these topics within the course of one semester, appropriate resources were made available to students to review these concepts. In addition, these concepts are introduced to the students in other classes at the School of Architecture such as building construction and environmental control systems. Further input of resources is required, which provide students an opportunity to draw connections between engineering principles and good practices in architectural design. The flipped class format implemented worked well, in creating opportunities for class and on-site activities, as well as maximizing one-on-one interactions of instructors with the students. The small class size of 4 architecture and 5 engineering students contributed to the effectiveness of this format. However, for further engagement of students in the course curriculum especially with larger class sizes, the presented information has to be reinforced with tests and quizzes. It was also noted that the preliminary walkthrough could be structured as an opportunity for students to use the documented information of building characteristics to inform subsequent tasks such as: experiment setup, measurements and survey. A preliminary checklist that would provide such guidance should be prepared by the instructor.

The collaboration with UC CBE proved to be helpful in establishing a basic questionnaire for the two casestudy buildings. However, the questionnaire could be customized to the class objectives and goals, which would enhance the value of the results and data being collected. For example, the questionnaire had numerous questions about the occupants' use of controls for lighting and temperature, however, the survey fell short on reviewing occupant comfort in dorm rooms on a regular basis.

\section{Integration with Engineering Students}

When considering integration with engineering and architecture students, the current interactions between students of both disciplines was found to be invigorating, but very limited. More common activities involving students from both disciplines would have enhanced the integration approach taken by this class. Examples of common activities include: Encouraging students of both disciplines to work in teams to examine selection of air distribution system and impact on acoustics in the buildings; selection, 
sizing and design of HVAC system and the impact of these design decisions on resultant IAQ; and assessing the interaction between passive and active systems implemented in the case-study buildings.

For the architectural component of the class the lectures provided information on all components of IEQ. However, it was observed that students were inclined to focus on a single IEQ component of their choice. It is recommended that synergies between IEQ components and energy consumption need to be explored. In addition, more time needs to be allocated towards working on integrated solutions. Class exercises that give students an opportunity to engage in such interdisciplinary discussions in order to understand these relations and come up with integrated solutions should be encouraged. For example: Direct solar radiation entering the building causes issues of glare as well as thermal comfort and can contribute to elevated space cooling loads. Acknowledgment of these interrelated issues would lead to architecture and engineering design teams to make more informed choices when deciding on facades and interior shading systems.

The discrepancy in the expectations between the two classes needs to be addressed. In the current scenario, the engineering class was a 1 credit class geared towards undergraduates, on the other hand the architecture class was a 3 credit class geared towards graduate students. In the future, similar expectations should be established for both groups of students, which could involve removing discrepancies in credits and levels. For the engineering students, it would be useful to expand this class to a two or three credit hour course. This would enable more robust analyses and more in depth studies of building systems as well as more detailed interactions with the architecture students. One can also consider interdisciplinary field visits to facilitate learning and questions from each group. An additional observation is that the engineering students, while well-grounded in theory of mechanical operations, were not exposed to actual equipment and field conditions. This was an added bonus of this class and one that can be expanded to include more site visits and combined building assessments with architectural students and building professionals.

\section{Use of Research to Innovate Education}

Structuring the class around a research project was a good way to involve both undergraduate and graduate students in addressing real time issues of building performance. Currently, formulation of hypotheses was based on the observations from a preliminary walkthrough. The students then worked over the course of the semester to answer the research question posed by a particular hypothesis. However, to enhance the appropriation of research in student education, potential areas of collaboration between disciplines may need to be identified and appropriate resources need to be provided and organized that facilitate such a collaboration. The resultant hypothesis needs to be developed upon with gain of understanding and knowledge over the course of the semester. For example, the preliminary hypothesis of 'Without a forced air ventilation system, the rooms will become stuffy and malodorous' formulated during the preliminary walkthrough could have been fine-tuned to 'A forced air ventilation system may not solve the issues of indoor air quality or building design and occupant education play an equally important role as do mechanical ventilation systems in assuring indoor air quality while mitigating the impacts of environmental pollutants and poor indoor air quality' or 'The current state of building design often neglects the complex interaction of occupants and building systems' as and when the information became available to the student and potential for collaborating with student from other discipline became more evident.

\section{SUMMARY AND CONCLUSIONS}

This paper describes the content, and structure of a class developed to address the research project sponsored by the EPA, which evaluates the indoor environmental quality and energy performance of LEED buildings, with the intent of creating guidelines that can be used by both architects and engineers to enhance the IEQ and energy performance of these buildings. The interdisciplinary format of the class emphasized the importance of collaboration between several disciplines especially architects and mechanical engineers towards optimizing building performance for both IEQ and energy consumption in future buildings. The paper also highlighted the importance of conducting research to questions, raised for the effective operation of Green buildings. 


\section{REFERENCES}

Anderson, L. W., and D. Krathwohl (Eds.). 2001. A taxonomy for learning, teaching, and assessing: A revision of Bloom's taxonomy of educational objectives. New York: Longman.

ASHRAE, 2009. Indoor Air Quality Guide Best Practices for Design, Construction, and Commissioning. American Society of Heating, Refrigerating and Air-Conditioning Engineers, Inc. Atlanta: Georgia.

ASHRAE, 2010. Performance Measurement Protocols for Commercial Buildings. American Society of Heating, Refrigeration and Air Conditioning Engineers, Atlanta, Georgia.

ASHRAE, 2011. Procedures for Commercial Building Energy Audits, Second Edition. American Society of Heating, Refrigerating and Air-Conditioning Engineers, Inc. Atlanta: Georgia.

ASHRAE, 2013. ASHRAE Standard 62.1 - 2013. Standard for Ventilation for Acceptable Indoor Air Quality. American Society of Heating, Refrigerating and Air-Conditioning Engineers, Inc. Atlanta: Georgia.

ASHRAE, 2014. ASHRAE Guideline-14, Measurement of Energy, Demand, and Water Savings. American Society of Heating, Refrigerating and Air-Conditioning Engineers, Inc. Atlanta: Georgia.

Bloom, B., M. Englehart, E. Furst, W. Hill, and D. Krathwohl. 1956. Taxonomy of educational objectives: The classification of educational goals. Handbook I: Cognitive domain. New York, Toronto: Longmans, Green.

Brame, C. 2013. Flipping the classroom. Vanderbilt University Center for Teaching. Web Access: http://cft.vanderbilt.edu/guides-sub-pages/flipping-the-classroom/

Center for the Built Environment (CBE). 2018. Occupant Indoor Environment Quality (IEQ) Survey. Berkeley, CA. Web: www.cbe.berkeley.edu/research/survey.htm

Cleveland, W. 1994. The Elements of Graphing Data. AT\&T Bell Laboratories, Hobbart Press, Summit, NJ.

Ellis, R. 2009. Field Guide to Learning Management. ASTD Learning Circuits.

Goldsmith, A., D. Hamilton, K. Hornsby and D. Wells. 2018. Interdisciplinary Approaches to Teaching. Science and Education Resource Center (SERC), Carlton College. Web Access: https://serc.carleton.edu/sp/library/interdisciplinary/index.html

GSA, 2011. Sound Matters: How to Achieve Acoustic Comfort in the Contemporary Office. General Services Administration. Web Access: https://www.wbdg.org/FFC/GSA/gsa soundmatters.pdf

Haglund, B. 2019. ARCH 571 Building Performance Evaluation. University of Idaho, Moscow ID. Web Access: https://www.webpages.uidaho.edu/Arch571/Arch471.htm

IPMVP. 2001. International Performance Measurement \& Verification Protocol - Volume 2. United States Department of Energy publication DOE/GO-102002-1187.

Lee, Y.S. and D.A. Guerin. 2010. Indoor Environmental Quality Differences Between Office Types in LEED-certified Buildings in the U.S. Building and Environment 45 Pgs. 1104 - 1112.

Lee, Y.S. and S.K. Kim. 2008. Indoor Environmental Quality in LEED-Certified Buildings in the US. Journal of Asian Architecture and Building Engineering. Volume 7 No.2. Pgs. 293 - 300. 
Mukhopadhyay, J., S. Sanderson, D. Elliot et al. 2019. An Evaluation of the Actual Energy and Indoor Environmental Quality Performance of On-campus Buildings Designed in Accordance with LEED Rating Criteria. Final Report for Environmental Protection Agency EPA-G2017-P3-Q2 - Built Environment. School of Architecture, Montana State University, Bozeman MT

NBI, 2017. Daylighting Pattern Guide. New Buildings Institute. Web Access: https://patternguide.advancedbuildings.net/about

Regnier, C. 2012 Guide to setting thermal comfort criteria and minimizing energy use in delivering thermal comfort. LBNL-6131E. Lawrence Berkeley National Laboratory, Berkeley CA.

Tukey, J. 1977. Exploratory Data Analysis. Addison-Wesley, Reading, MA.

USGBC, 2009. Leadership in Energy \& Environmental Design - Reference Guide for Building Design and Construction v3. U.S. Green Building Council, Washington DC.

USGBC, 2013. Leadership in Energy \& Environmental Design - Reference Guide for Building Design and Construction v4. U.S. Green Building Council, Washington DC.

\section{AKNOWLEDGEMENTS}

The project and class described in this paper was supported by funds from the Environmental Protection Agency's People, Prosperity and the Planet - Program. The authors would also like to thank Aleesha Redmon at the Montana State University Writing Center for patiently proofreading the paper. 